\title{
Structural and Optical Studies of Cadmium Sulfide Quantum Dot- Graphene Oxide-Chitosan Nanocomposite Thin Film as a Novel SPR Spectroscopy Active Layer
}

\author{
Silvan Saleviter, ${ }^{1}$ Yap Wing Fen $\mathbb{D}^{1,2}$ Nur Alia Sheh Omar, ${ }^{1}$ \\ Wan Mohd Ebtisyam Mustaqim Mohd Daniyal, ${ }^{1}$ Jaafar Abdullah, $^{3}$ \\ and Mohd Hazani Mat Zaid ${ }^{3}$ \\ ${ }^{1}$ Functional Devices Laboratory, Institute of Advanced Technology, Universiti Putra Malaysia, 43400 UPM Serdang, \\ Selangor, Malaysia \\ ${ }^{2}$ Department of Physics, Faculty of Science, Universiti Putra Malaysia, 43400 UPM Serdang, Selangor, Malaysia \\ ${ }^{3}$ Department of Chemistry, Faculty of Science, Universiti Putra Malaysia, 43400 UPM Serdang, Selangor, Malaysia \\ Correspondence should be addressed to Yap Wing Fen; yapwingfen@gmail.com
}

Received 11 July 2018; Revised 24 September 2018; Accepted 26 September 2018; Published 2 December 2018

Academic Editor: Rajesh R. Naik

Copyright (C) 2018 Silvan Saleviter et al. This is an open access article distributed under the Creative Commons Attribution License, which permits unrestricted use, distribution, and reproduction in any medium, provided the original work is properly cited.

\begin{abstract}
The aim of this study is to prepare and study the cadmium sulfide quantum dot-graphene oxide-chitosan composite thin film. This composite material was coated on top of the gold layer by a spin-coating technique as a modification of the active layer for metal ion sensing using surface plasmon resonance spectroscopy (SPR). The composite material was prepared using a simple wet solution mixing method. An atomic force microscope (AFM) shows that the addition of GO increased the roughness of the composite thin film and the presence of CdS QDs cannot be observed as the size of the QDs are very small. The morphology of the nanocomposite material was observed using transmission electron microscopy (TEM). From the TEM images, it is observed that the materials mixed to form a nanocomposite material. The optical properties of the thin film via UV-Vis spectroscopy shows that the absorbance peaks of the thin film can be observed around $220 \mathrm{~nm}$ to near $300 \mathrm{~nm}$, and the band gaps are around $4.0 \mathrm{eV}$. Lastly, the prepared thin film was tested as an active layer for metal ion detection via surface plasmon resonance (SPR), where the angle shift was observed to show that the prepared thin film has high potential for $\mathrm{Co}^{2+}$ ion detection.
\end{abstract}

\section{Introduction}

In recent years, a lot of novel materials have been discovered and studied. One of the most promising materials is chitosan. Chitosan is a semicrystalline polymer material that is derived from chitin by deacetylation under alkaline conditions. Chitosan is said to be the most important chitin derivative, which is cationic in nature and has good adsorption capacity and film-forming capability [1]. It is used to produce films, hydrogels, and fibers where it is mostly used in the biomedical field because of its biocompatibility [1-3]. However, the stability of chitosan is low because of its hydrophilic character and $\mathrm{pH}$ sensitivity $[1,2]$. Therefore, a number of techniques have been used to improve the mechanical and chemical properties of chitosan. One of the techniques is crosslinking chitosan with a reagent such as ionophore or glutaraldehyde [4-6]. Chitosan can also be reinforced by blending it with other novel materials such as graphene oxide [7-9].

Quantum dots (QDs) on the other hand are nanosized crystals which are composed of semiconducting materials. In other words, they are actually tiny semiconductors that have the ability to convert incoming energy. As a material for semiconductor nanostructures, a quantum dot confines the motion of conduction band electrons, valence band holes, or excitons, which means it contains a small finite number of conduction band electrons, valence band holes, or excitons. The size of this nanoparticle is usually around several 
nanometers. Due to these confinement effects, QDs exhibit unique and remarkable physical and chemical properties compared to bulky materials. Some of the advantages of QDs over other bulky materials include a broader absorption spectra, narrow emission spectra, better photostability, and longer fluorescent lifetime after excitation [10]. Furthermore, its properties can be greatly affected by only altering the particle size without changing the chemical composition [11].

Quantum dots are made up of atoms from group II-VI, group III-V, or group IV-VI elements in the periodic table [12]. In the past few decades, QDs have attracted considerable attention due to their special properties. Cadmium sulfide quantum dots (CdS QDs) are one of the most studied QDs which are composed of group II to VI element semiconductors. There is a considerable amount of information from research that can be searched and obtained from various sources regarding the preparation, properties, and applications of CdS QDs [13-15]. Cadmium sulfide-based quantum dots are promising materials for the development of optics, optoelectronics, medicine, and sensor technology $[16,17]$. CdS QDs have been widely used in fluorescence sensors for metal ion-sensing applications $[18,19]$. To the best of our knowledge, this material has not been used as a surface plasmon resonance (SPR) active layer for the detection of metal ions.

In the present study, quantum dots, chitosan, and graphene oxide are mixed to form a composite material thin film, since it is believed that the properties of composite materials are better compared to the properties of the individual materials. In addition, an attempt was made to apply the composite material thin film onto the surface of a gold glass substrate which will be applied as an active layer in the surface plasmon resonance technique for metal ion sensing [20-22].

\section{Materials and Methods}

2.1. Materials and Reagents. Medium molecular weight (MMW) chitosan with an MW of 190,000-310,000 and degree of deacetylation of $75-85 \%$, acetic acid (assay $\geq 99.7 \%$ ) was purchased from Sigma-Aldrich (St. Louis, MO, USA). Cadmium chloride decahydrate $\left(\mathrm{CdCl}_{2} \cdot 10 \mathrm{H}_{2} \mathrm{O}\right)$, mercaptoacetic acid (MPA) (HS- $\left.\mathrm{CH}_{2}-\mathrm{COOH}\right)$, and disodium sulfide nonahydrate $\left(\mathrm{Na}_{2} \mathrm{~S} \cdot 9 \mathrm{H}_{2} \mathrm{O}\right)$ were purchased from $\mathrm{R} \& \mathrm{M}$ Chemicals. Graphene oxide (GO) $(4 \mathrm{mg} / \mathrm{ml})$ was purchased from Graphenea (Cambridge, MA, USA).

2.2. Preparation of Chemicals. All chemicals used were of analytical grade and deionized water was used for all solution preparations. At first, a chitosan solution was prepared by dissolving $0.4 \mathrm{~g}$ of medium molecular weight chitosan that was purchased from Sigma-Aldrich with $50 \mathrm{ml}$ of $1 \%$ acetic acid [23]. The cadmium sulfide quantum dots were prepared by a simple wet process [16]. It started by dissolving $0.5 \mathrm{mmol}$ of MPA and $0.5 \mathrm{mmol}$ of $\mathrm{CdCl}_{2} \cdot 10 \mathrm{H}_{2} \mathrm{O}$ by adding $250 \mathrm{ml}$ of $\mathrm{ddH}_{2} \mathrm{O}$ water in a $500 \mathrm{ml}$ beaker. Then, the $\mathrm{pH}$ of the solution was adjusted to 6.0 by adding the $\mathrm{NaOH}$ solution (1M) dropwise with constant stirring. Subsequently, the solution was purged with nitrogen gas for at least $60 \mathrm{~min}$ under vigorous stirring. Sodium sulfide $\left(\mathrm{Na}_{2} \mathrm{~S} \cdot 9 \mathrm{H}_{2} \mathrm{O}\right)(0.5 \mathrm{mmol})$ was then added dropwise into the stirred solution until the clear yellowish suspension of CdS QDs was obtained. The obtained aqueous CdS QDs were then quenched at $0^{\circ} \mathrm{C}$ in the freezer $(45 \mathrm{~min})$ and stored in a refrigerator at $4^{\circ} \mathrm{C}$. Finally, a composite solution with a $1: 1: 1$ ratio was prepared by stirring $10 \mathrm{ml}$ of chitosan, CdS QDs, and GO solution using a magnetic stirrer for 1 hour and then sonicating again for one hour.

2.3. Preparation of Thin Film. Glass cover slips ( $24 \mathrm{~mm} \times 24 \mathrm{~mm} \times 0.1 \mathrm{~mm}$, Menzel-Glaser, Germany) were cleaned using acetone to remove dirt and impurities on the surface of the glass slide before any coating process. The glass slides were first deposited with a thin gold layer using an SC7640 sputter coater [24]. Then, the spin-coating technique (Specialty Coating System, P-6708D) was used to produce a thin layer of CdS QD-GO-chitosan composite. Approximately $0.55 \mathrm{ml}$ of the composite solution of CdS QD-GOchitosan was placed on the gold layer covering the majority of the surface. The glass cover slip was spun at $4000 \mathrm{rev} /$ min for $30 \mathrm{~s}$ to produce the composite thin film.

2.4. Characterization and Optical Study of Thin Film. An atomic force microscope (AFM) (Bruker Multimode 8) was used to observe the changes of the surface morphology of the composite thin film with the base material thin films. The morphology of the composite material was observed by using transmission electron microscopy (TEM) (JEOL JEM2100). The optical properties of the thin film was studied using UV-Vis spectroscopy (UV-3600, Shimadzu). The optical sensor test was then carried out via surface plasmon resonance (SPR) spectroscopy by observing the angle shift of the active composite layer in contact with deionized water and cobalt ion solution.

2.5. Surface Plasmon Resonance (SPR) System. An optical spectroscopy was designed to test the capability of the nanocomposite thin film for the $\mathrm{Co}^{2+}$ ion. A $5 \mathrm{~mW} \mathrm{He-Ne} \mathrm{laser}$ $(\lambda=632.8 \mathrm{~nm})$ was $\mathrm{p}$-polarized and directed to a prism (refractive index, $n=1.77861$ at $632.8 \mathrm{~nm}$ ). The optical setup of this SPR technique consists of a He-Ne laser, an optical stage driven by a stepper motor with a resolution of $0.001^{\circ}$ (Newport MM3000), a polarizer, and an optical chopper (SR540). The He-Ne laser beam was incident on to the prism (refractive index of 1.77861), passed through the sample (derivative thin film), and the reflected beam was detected by a large area photodiode. The signal was then processed by the lock-in amplifier (SR530) [25] with a glass cover slip and coated with gold/CdS QD-GO-chitosan films attached onto one side of the prism. A cell was constructed and attached to the gold/CdS QD-GO-chitosan film surface to hold the Co (II) ion solution. A schematic diagram of the SPR setup is shown in Figure 1. The prism and the cell were mounted on a rotating plate to control the angle of the incident light. The reflected beam was detected by a sensitive photodiode and then processed by the lock-in amplifier (SR530). 


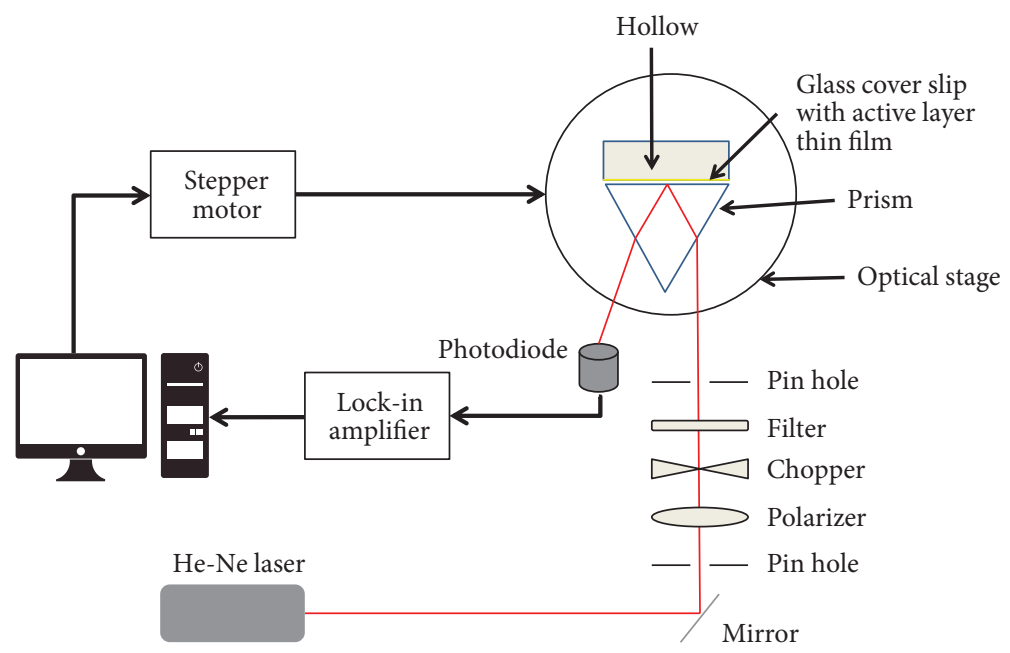

FIGURE 1: Schematic diagram of the SPR setup.
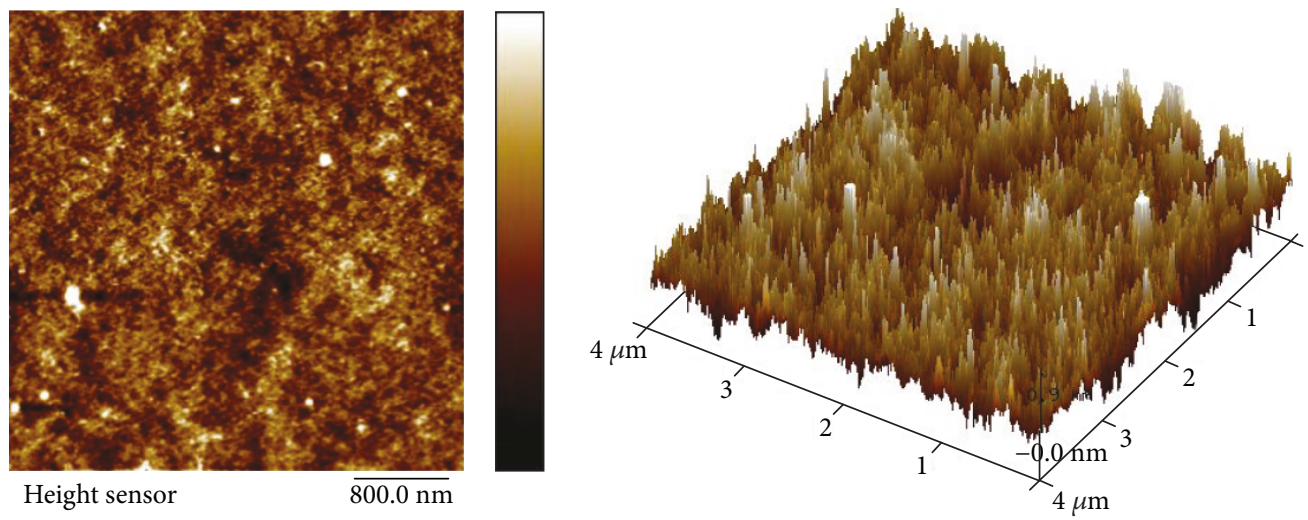

Figure 2: AFM images of the chitosan thin film.

\section{Results and Discussion}

3.1. Surface Morphology of Thin Film. Atomic force microscopy analysis is used as a quantitative measurement of the nanometric-dimensional surface roughness and for visual observation of the deposited film nanotexture [26]. Twodimensional (2D) and three-dimensional (3D) AFM images of the chitosan, chitosan-GO, and CdS QD-GO-chitosan thin films are shown in Figures 2, 3, and 4, respectively. From Figure 2, it is observed that the granular surface of chitosan seems to have a smooth surface and is well distributed on top of the glass substrate. The addition of graphene oxide (Figure 3) shows that graphene oxide mixes well in the chitosan matrix, and the addition of GO in the chitosan increases the surface roughness of the chitosan-GO composite thin film from $0.216 \mathrm{~nm}$ to $0.948 \mathrm{~nm}$. The graphene sheets can be clearly seen with their addition to the granular surface of the chitosan. In addition, the increase of surface roughness may be due to the graphene sheets of the graphene oxide. On the other hand, the surface roughness of a chitosanGO-CdS QD thin film is $0.627 \mathrm{~nm}$. It can be seen from Figure 4 that the graphene sheets of graphene oxide are lesser compared to the graphene sheets present in the chitosan-GO thin film in Figure 3.
3.2. Morphology of the Composite Material. The composite solution was first diluted using deionized water with the ratio of $1: 10$ before the solution was dropped on top of the $\mathrm{Cu}$ grid to prevent a thick film from depositing on the $\mathrm{Cu}$ grid. The morphology of the CdS QD-GOchitosan nanocomposite solution was investigated using the TEM technique as shown in Figure 5. From the figure, the TEM image shows a thin extended wrinkled sheet of GO with chitosan covering the surface of GO [27]. It can also be seen from the figure that CdS QDs were immobilized on the surface of the GO sheet with a few free CdS QDs observed [28]. This figure shows the presence of the three elements as a composite material. Figure 6 shows the distribution of chitosan particles on GO sheets with greater magnification and it confirmed the granular surface contributed by the chitosan particle as shown in the AFM result.

3.3. Optical Studies of Thin Film. The optical properties of the thin films were confirmed by observing the absorbance spectrum at a different wavelength in the range of $220 \mathrm{~nm}$ to $800 \mathrm{~nm}$. The absorbance curves of the composite thin film materials are shown in Figure 7. The figure shows the absorption spectra of different materials that make the chitosan- 


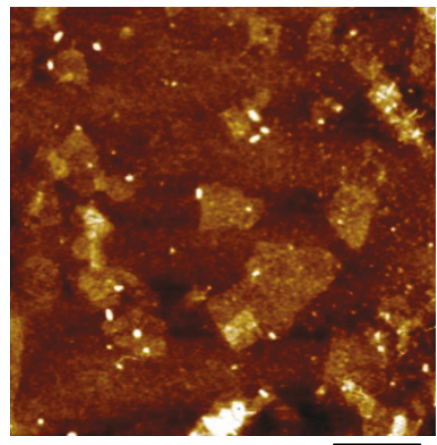

Height sensor

$\overline{800.0 \mathrm{~nm}}$

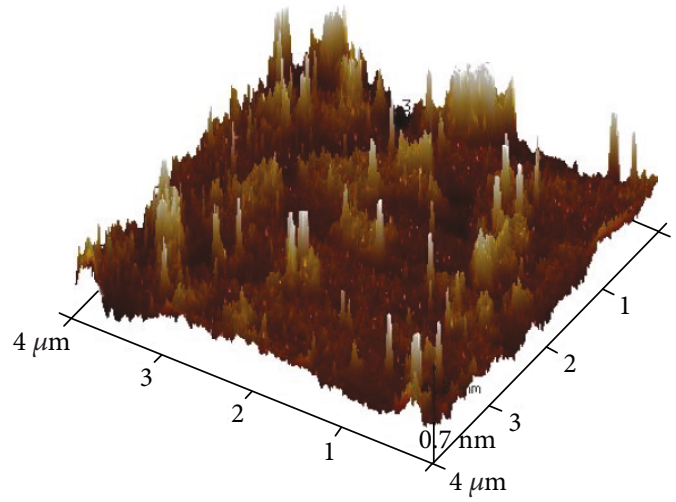

Figure 3: AFM images of the chitosan-GO thin film.
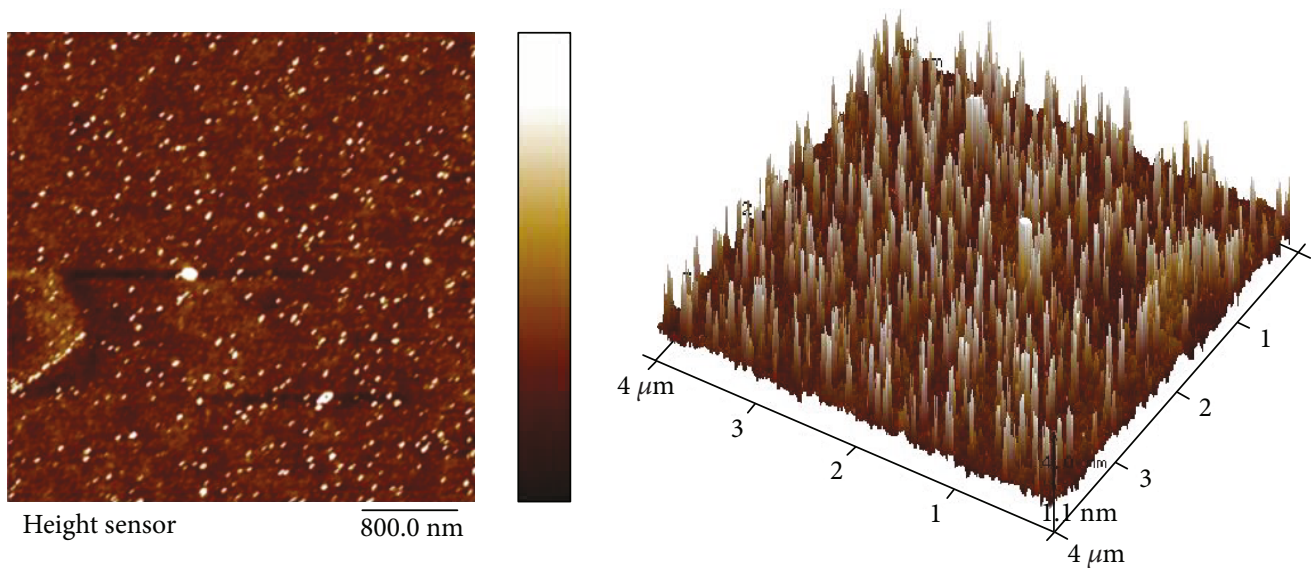

Figure 4: AFM images of the chitosan-GO-CdS QDs thin film.

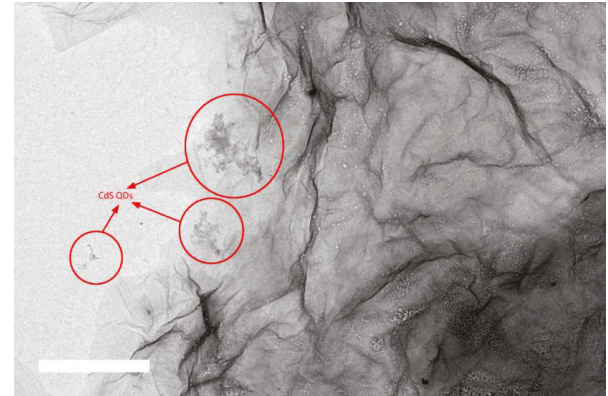

FIGURE 5: TEM image of the CdS QD-GO-chitosan nanocomposite material (scale: $1 \mu \mathrm{m}$ ).

CdS QD-GO composite thin film. As shown in the figure, chitosan-GO shows the highest absorption value followed by the CdS QD-GO-chitosan, and lastly chitosan only. It is said that absorbance may depend on the atomic number and density of the material [29]. From the figure, the absorbance peaks of GO can be seen in the range of $230 \mathrm{~nm}$ to $280 \mathrm{~nm}$. This result is the same as that of Zheng et al. in 2013 who stated that the typical absorption of GO is observed between $225 \mathrm{~nm}$ and $270 \mathrm{~nm}$. From Figure 7, it can be observed that both chitosan-GO and chitosan-GO-CdS QD

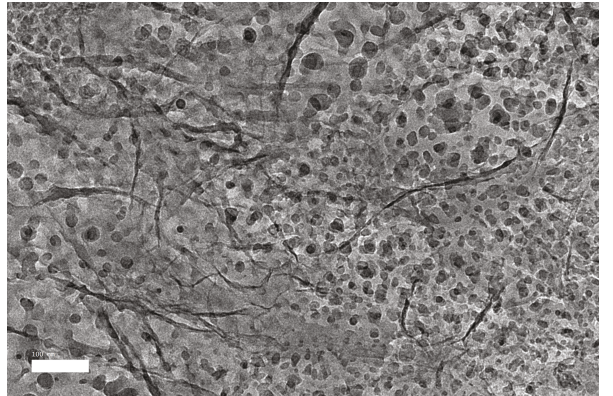

FIGURE 6: TEM image of chitosan on top of the GO layer (scale: $100 \mathrm{~nm})$.

composite thin films produced a peak at approximately $228 \mathrm{~nm}$. The absorption peak at about $220 \mathrm{~nm}$ to $240 \mathrm{~nm}$ corresponds to the $\pi \rightarrow \pi^{*}$ transition of the $\mathrm{C}=\mathrm{C}$ bond [30]. However, there is no peak seen at that wavelength for the chitosan thin film. Its absorption peak near $300 \mathrm{~nm}$ can also be assigned to the $\pi \rightarrow \pi^{*}$ transitions of the $\mathrm{C}=\mathrm{O}$ bond [31]. The peaks for both the chitosan-GO thin film and CdS QD-GO-chitosan thin film are almost similar except for the peak at approximately $250 \mathrm{~nm}$ where the peak for the chitosan-GO thin film is more obvious. 


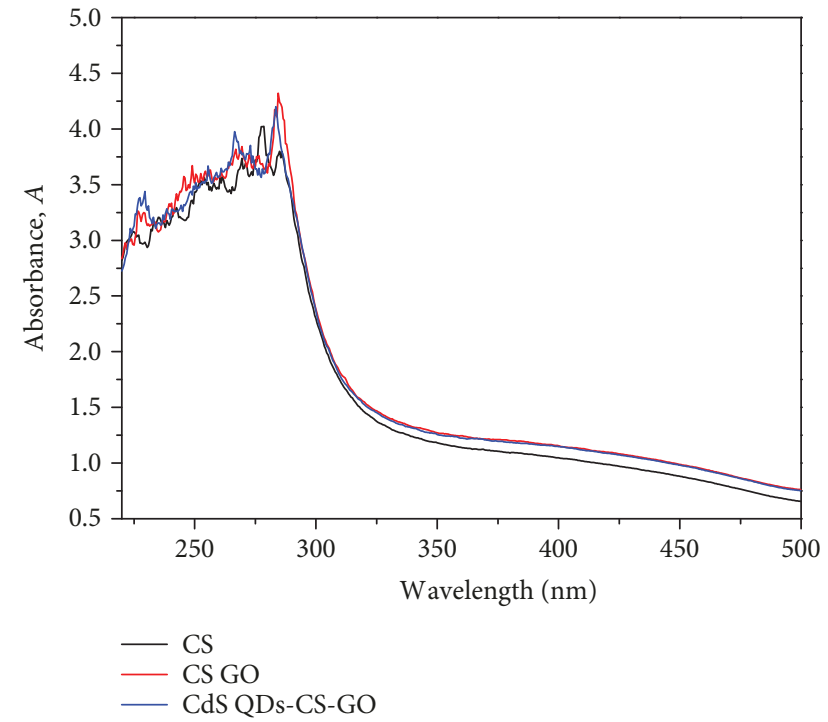

FIGURE 7: UV-vis absorption spectra of the thin films.

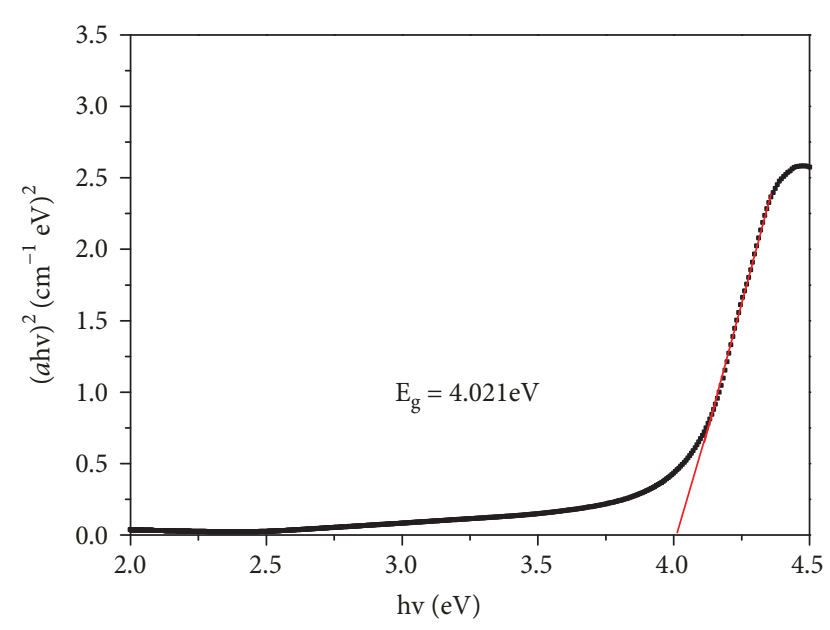

FIgURE 8: Optical band gap of the chitosan thin film.

3.4. Band Gap of the Thin Film. The optical band gap of the thin films was obtained by applying the Tauc relation:

$$
a=\frac{k\left(h v-E_{g}\right)^{1 / 2}}{h v}
$$

where it can be rearranged into

$$
(a h v)^{2}=k\left(h v-E_{g}\right)
$$

where the absorption coefficient, $\alpha$ can be obtained by extracting the UV-Vis data. $h v$ is the photon energy. $k$ is a constant. $E g$ is the band gap energy. The obtained optical band gaps of chitosan, GO, chitosan-GO, and CdS QDGO-chitosan thin film are shown in Figures 8, 9, 10, and 11 , respectively. It can be seen from the figures that the values of the energy band gap of the thin films are slightly different. The graphene oxide thin film has the lowest energy band gap at $3.954 \mathrm{eV}$, while chitosan has a slightly higher band gap of

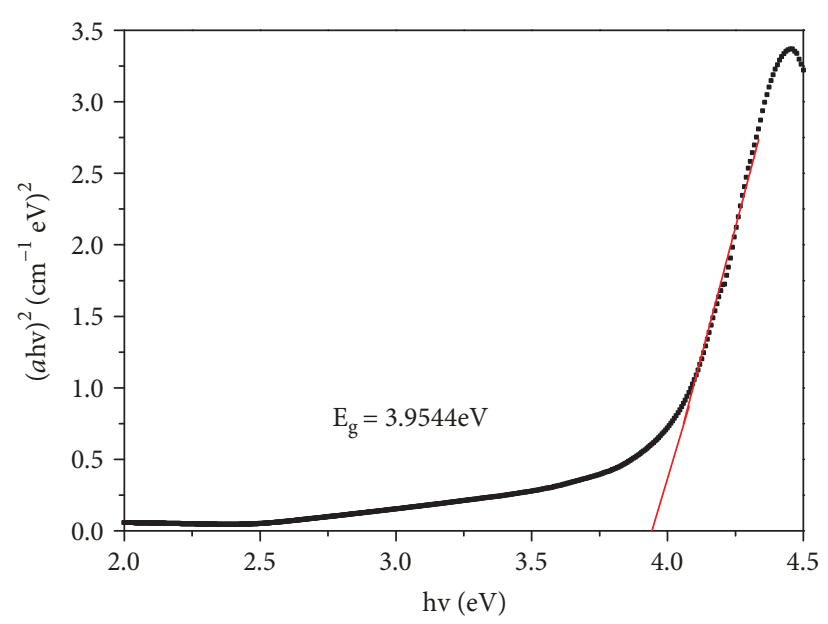

Figure 9: Optical band gap of the GO thin film.

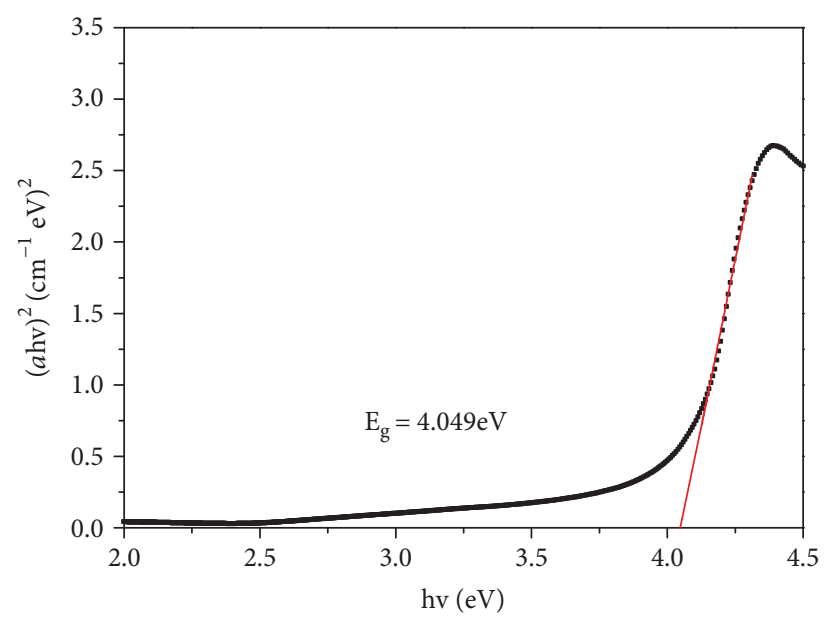

FIgURE 10: Optical band gap of the chitosan-GO composite thin film.

$4.021 \mathrm{eV}$. The mixture of chitosan and GO thin film produced a band gap of $4.049 \mathrm{eV}$. On the other hand, the addition of CdS QDs slightly lowered the band gap of the composite thin film to $4.033 \mathrm{eV}$. GO has the lowest band gap due to the excellent conductivity of graphene that provides better electron transportation between the conduction band and valence band [32-34]. Overall, there are no major changes to the optical band gap by the addition of GO and CdS QDs into the chitosan matrix which is in the range of $4.021 \mathrm{eV}$ to 4.049 as shown in the figures. This may be due to the biopolymer nature of chitosan as the main matrix [2].

3.5. SPR Test of the Thin Film. The active layer thin film was tested with deionized water with $0.01 \mathrm{ppm}, 0.1 \mathrm{ppm}, 1 \mathrm{ppm}$, and $10 \mathrm{ppm}$ of cobalt ion via surface plasmon resonance. Surface plasmon resonance spectroscopy worked by observing the changes of the refractive index of the active layer due to the interaction of the active layer with the targeted metal ion [35]. Figure 12 shows that there is a resonance angle shift by observing the SPR curve of the active layer in contact with 


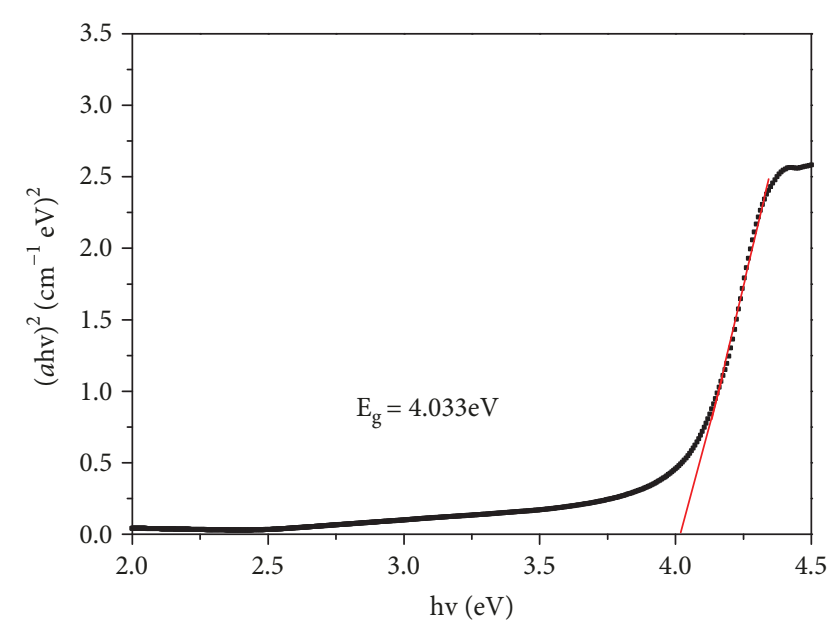

FIgURE 11: Optical band gap of the chitosan-GO-CdS QD composite thin film.

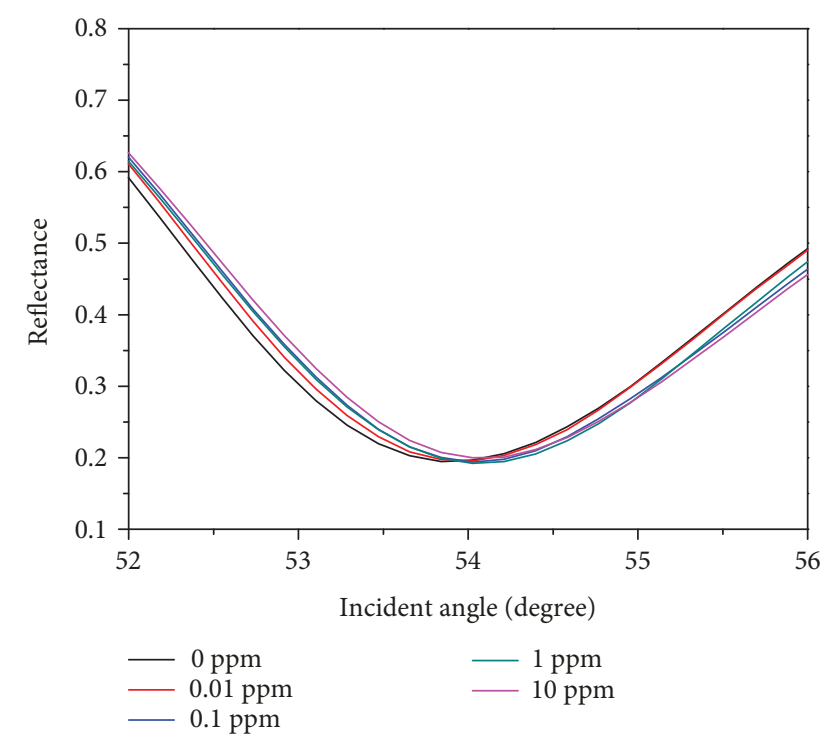

FIGURE 12: SPR curves of the active layer in contact with deionized water with $0.01 \mathrm{ppm}, 0.1 \mathrm{ppm}, 1 \mathrm{ppm}$, and $10 \mathrm{ppm}$ cobalt ion.

the deionized water and cobalt ion. The angle shift of the SPR signal increases from $0.01289^{\circ}, 0.09237^{\circ}, 0.11063^{\circ}$, and $0.18367^{\circ}$, respectively, for $0.01 \mathrm{ppm}, 0.1 \mathrm{ppm}, 1 \mathrm{ppm}$, and $10 \mathrm{ppm}$. This shift was contributed by the attachment of the metal ion onto the active layer thin film [36-38]. The attachment of the metal ion with the active layer changes the refractive index of the active layer hence causing a shift in the resonance angle [39-41].

\section{Conclusions}

In summary, the physical and optical properties of the CdS QD-GO-chitosan nanocomposite thin film were successfully prepared and studied. The addition of GO into the matrix increases the absorbance of the composite thin film and the band gap of the nanocomposite thin film is around $4.0 \mathrm{eV}$. The surface of the nanocomposite thin film is relatively well distributed and the presence of graphene sheets increases the surface roughness as confirmed by AFM and TEM results. Finally, the thin film gave some response to the metal ion binding by comparing the SPR curve of deionized water and cobalt ion in contact with the active layer. It can be concluded that the thin film has high potential for metal ion sensing using surface plasmon resonance spectroscopy.

\section{Data Availability}

The data used to support the findings of this study are available from the corresponding author upon request.

\section{Conflicts of Interest}

The authors declare that they have no conflicts of interest.

\section{Acknowledgments}

The authors would like to thank the Malaysian Government for the fund support through Putra Grant Universiti Putra Malaysia (Putra Grant 9531500 and 9627300). The laboratory facilities provided by the Department of Physics, Department of Chemistry and the Institute of Advanced Technology, Universiti Putra Malaysia, are also acknowledged.

\section{References}

[1] C. K. S. Pillai, W. Paul, and C. P. Sharma, "Chitin and chitosan polymers: chemistry, solubility and fiber formation," Progress in Polymer Science, vol. 34, no. 7, pp. 641-678, 2009.

[2] M. Rinaudo, "Chitin and chitosan: properties and applications," Progress in Polymer Science, vol. 31, no. 7, pp. 603632, 2006.

[3] M. N. V. Ravi Kumar, "A review of chitin and chitosan applications," Reactive and Functional Polymers, vol. 46, no. 1, pp. 1-27, 2000.

[4] S. Kumar, N. Nigam, T. Ghosh, P. K. Dutta, R. S. Yadav, and A. C. Pandey, "Preparation, characterization, and optical properties of a chitosan-anthraldehyde crosslinkable film," Journal of Applied Polymer Science, vol. 115, no. 5, pp. 3056-3062, 2010.

[5] Y. W. Fen, W. M. M. Yunus, N. A. Yusof, N. S. Ishak, N. A. S. Omar, and A. A. Zainudin, "Preparation, characterization and optical properties of ionophore doped chitosan biopolymer thin film and its potential application for sensing metal ion," Optik-International Journal for Light and Electron Optics, vol. 126, no. 23, pp. 4688-4692, 2015.

[6] S. Kumar, P. K. Dutta, and P. Sen, "Preparation and characterization of optical property of crosslinkable film of chitosan with 2-thiophenecarboxaldehyde," Carbohydrate Polymers, vol. 80, no. 2, pp. 563-569, 2010.

[7] A. A. Zainudin, Y. W. Fen, N. A. Yusof, and N. A. S. Omar, "Structural, optical and sensing properties of ionophore doped graphene based bionanocomposite thin film," Optik, vol. 144, pp. 308-315, 2017.

[8] S. Kumar and J. Koh, "Physiochemical and optical properties of chitosan based graphene oxide bionanocomposite," International Journal of Biological Macromolecules, vol. 70, pp. 559564, 2014.

[9] D. Han, L. Yan, W. Chen, and W. Li, "Preparation of chitosan/ graphene oxide composite film with enhanced mechanical 
strength in the wet state," Carbohydrate Polymers, vol. 83, no. 2, pp. 653-658, 2011.

[10] S. S. Liji Sobhana, M. Vimala Devi, T. P. Sastry, and A. B. Mandal, "CdS quantum dots for measurement of the sizedependent optical properties of thiol capping," Journal of Nanoparticle Research, vol. 13, no. 4, pp. 1747-1757, 2011.

[11] D. Bera, L. Qian, T. K. Tseng, and P. H. Holloway, "Quantum dots and their multimodal applications: a review," Materials, vol. 3, no. 4, pp. 2260-2345, 2010.

[12] C. Frigerio, D. S. M. Ribeiro, S. S. M. Rodrigues et al., "Application of quantum dots as analytical tools in automated chemical analysis: a review," Analytica Chimica Acta, vol. 735, pp. 9-22, 2012.

[13] Z. Tshemese, S. Mlowe, N. Revaprasadu, and N. Deenadayalu, "Synthesis of CdS quantum dots in an imidazolium based ionic liquid," Materials Science in Semiconductor Processing, vol. 71, pp. 258-262, 2017.

[14] D. Šajinović, Z. V. Šaponjić, N. Cvjetićanin, M. MarinovićCincović, and J. M. Nedeljković, "Synthesis and characterization of CdS quantum dots-polystyrene composite," Chemical Physics Letters, vol. 329, no. 1-2, pp. 168-172, 2000.

[15] S. Ben Taieb, T. N. Pham Truong, S. Chaguetmi et al., "An easy-to achieve approach for the fabrication of CdS QDs sensitized $\mathrm{TiO}_{2}$ nanotubes and their enhanced photoelectrochemical performance," Journal of Photochemistry and Photobiology A: Chemistry, vol. 332, pp. 337-344, 2017.

[16] M. H. Mat Zaid, J. Abdullah, N. A. Yusof et al., "PNA biosensor based on reduced graphene oxide/water soluble quantum dots for the detection of Mycobacterium tuberculosis," Sensors and Actuators B: Chemical, vol. 241, pp. 10241034, 2017.

[17] M. H. M. Zaid and J. Abdullah, "Preparation and characterization of amine functionalized graphene oxide with water soluble quantum dots for sensing material," $A I P$ Conference Proceedings, vol. 1877, no. 1, article 040002, 2017.

[18] S. N. Wang, J. Zhu, X. Li, J. J. Li, and J. W. Zhao, "Fluorescence turn-on sensing of trace cadmium ions based on EDTA-etched CdTe@CdS quantum dot," Spectrochimica Acta Part A: Molecular and Biomolecular Spectroscopy, vol. 201, pp. 119-127, 2018.

[19] Y. Fan, Y. Q. Cai, H. J. Liu, and Y. Chen, "CdS quantum dots capped with hyperbranched graft copolymers: role of hyperbranched shell in fluorescence and selective mercury-sensing," Sensors and Actuators B: Chemical, vol. 251, pp. 171-179, 2017.

[20] L. Kee, J. L. Y. Chyi, Z. A. Talib et al., "Synthesis of zinc selenide/graphene oxide composite via direct and indirect hydrothermal method," Sains Malaysiana, vol. 45, no. 8, pp. 1201-1206, 2016.

[21] W. M. E. M. M. Daniyal, Y. W. Fen, J. Abdullah, S. Saleviter, and N. A. Sheh Omar, "Preparation and characterization of hexadecyltrimethylammonium bromide modified nanocrystalline cellulose/graphene oxide composite thin film and its potential in sensing copper ion using surface plasmon resonance technique," Optik, vol. 173, pp. 71-77, 2018.

[22] S. Saleviter, Y. W. Fen, N. A. S. Omar, A. A. Zainudin, and W. M. E. M. M. Daniyal, "Optical and structural characterization of immobilized 4-(2-pyridylazo) resorcinol in chitosangraphene oxide composite thin film and its potential for
$\mathrm{Co}^{2+}$ sensing using surface plasmon resonance technique," Results in Physics, vol. 11, pp. 118-122, 2018.

[23] Y. W. Fen, W. M. M. Yunus, and Z. A. Talib, "Analysis of $\mathrm{Pb}$ (II) ion sensing by crosslinked chitosan thin film using surface plasmon resonance spectroscopy," Optik-International Journal for Light and Electron Optics, vol. 124, no. 2, pp. 126-133, 2013.

[24] Y. W. Fen, W. M. M. Yunus, Z. A. Talib, and N. A. Yusof, "Development of surface plasmon resonance sensor for determining zinc ion using novel active nanolayers as probe," Spectrochimica Acta Part A: Molecular and Biomolecular Spectroscopy, vol. 134, pp. 48-52, 2015.

[25] S. Saleviter, Y. W. Fen, N. A. S. Omar, A. A. Zainudin, and N. A. Yusof, "Development of optical sensor for determination of Co (II) based on surface plasmon resonance phenomenon," Sensor Letters, vol. 15, no. 10, pp. 862-867, 2017.

[26] B. R. Kumar and T. S. Rao, "AFM studies on surface morphology, topography and texture of nanostructured zinc aluminum oxide thin films," Digest Journal of Nanomaterials and Biostructures, vol. 7, no. 4, pp. 1881-1889, 2012.

[27] K. Bustos-Ramírez, A. Martínez-Hernández, G. MartínezBarrera, M. Icaza, V. Castaño, and C. Velasco-Santos, "Covalently bonded chitosan on graphene oxide via redox reaction," Materials, vol. 6, no. 3, pp. 911-926, 2013.

[28] T. A. Pham, B. C. Choi, and Y. T. Jeong, "Facile covalent immobilization of cadmium sulfide quantum dots on graphene oxide nanosheets: preparation, characterization, and optical properties," Nanotechnology, vol. 21, no. 46, pp. 465603-465612, 2010.

[29] M. S. Eluyemi, M. A. Eleruja, A. V. Adedeji et al., "Synthesis and characterization of graphene oxide and reduced graphene oxide thin films deposited by spray pyrolysis method," Graphene, vol. 05, no. 03, pp. 143-154, 2016.

[30] T. Wang, S. Zhang, C. Mao et al., "Enhanced electrochemiluminescence of CdSe quantum dots composited with graphene oxide and chitosan for sensitive sensor," Biosensors and Bioelectronics, vol. 31, no. 1, pp. 369-375, 2012.

[31] Rattana, S. Chaiyakun, N. Witit-Anun et al., "Preparation and characterization of graphene oxide nanosheets," Procedia Engineering, vol. 32, pp. 759-764, 2012.

[32] A. Hunt, E. Z. Kurmaev, and A. Moewes, "Band gap engineering of graphene oxide by chemical modification," Carbon, vol. 75, pp. 366-371, 2014.

[33] S. K. Hazra and S. Basu, "Graphene-oxide nano composites for chemical sensor applications," C, vol. 2, no. 2, p. 12, 2016.

[34] Y. Zhu, S. Murali, W. Cai et al., "Graphene and graphene oxide: synthesis, properties, and applications," Advanced Materials, vol. 22, no. 35, pp. 3906-3924, 2010.

[35] Y. W. Fen and W. M. M. Yunus, "Characterization of the optical properties of heavy metal ions using surface plasmon resonance technique," Optics and Photonics Journal, vol. 1, no. 3, pp. 116-123, 2011.

[36] N. A. S. Omar, Y. W. Fen, J. Abdullah, C. E. N. C. E. Chik, and M. A. Mahdi, "Development of an optical sensor based on surface plasmon resonance phenomenon for diagnosis of dengue virus E-protein," Sensing and Bio-Sensing Research, vol. 20, pp. 16-21, 2018.

[37] Y. W. Fen, W. M. M. Yunus, and N. A. Yusof, "Surface plasmon resonance optical sensor for detection of $\mathrm{Pb}^{2+}$ based on immobilized p-tert-butylcalix[4]arene-tetrakis in 
chitosan thin film as an active layer," Sensors and Actuators B: Chemical, vol. 171-172, pp. 287-293, 2012.

[38] A. A. Zainudin, Y. W. Fen, N. A. Yusof, S. H. Al-Rekabi, M. A. Mahdi, and N. A. S. Omar, "Incorporation of surface plasmon resonance with novel valinomycin doped chitosan-graphene oxide thin film for sensing potassium ion," Spectrochimica Acta Part A: Molecular and Biomolecular Spectroscopy, vol. 191, pp. 111-115, 2018.

[39] Y. W. Fen, W. M. M. Yunus, M. M. Moksin, Z. A. Talib, and N. A. Yusof, "Surface plasmon resonance optical sensor for mercury ion detection by crosslinked chitosan thin film," Journal of Optoelectronics and Advanced Materials, vol. 13, no. 2-4, pp. 273-279, 2011.

[40] W. M. E. M. M. Daniyal, S. Saleviter, and Y. W. Fen, “Development of surface plasmon resonance spectroscopy for metal ion detection," Sensors and Materials, vol. 30, no. 9, pp. 20232038, 2018.

[41] S. H. Al-Rekabi, Y. Mustapha Kamil, M. H. Abu Bakar et al., "Hydrous ferric oxide-magnetite-reduced graphene oxide nanocomposite for optical detection of arsenic using surface plasmon resonance," Optics \& Laser Technology, vol. 111, pp. 417-423, 2019. 


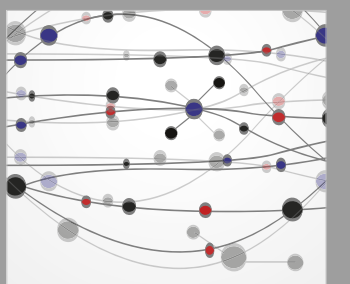

The Scientific World Journal
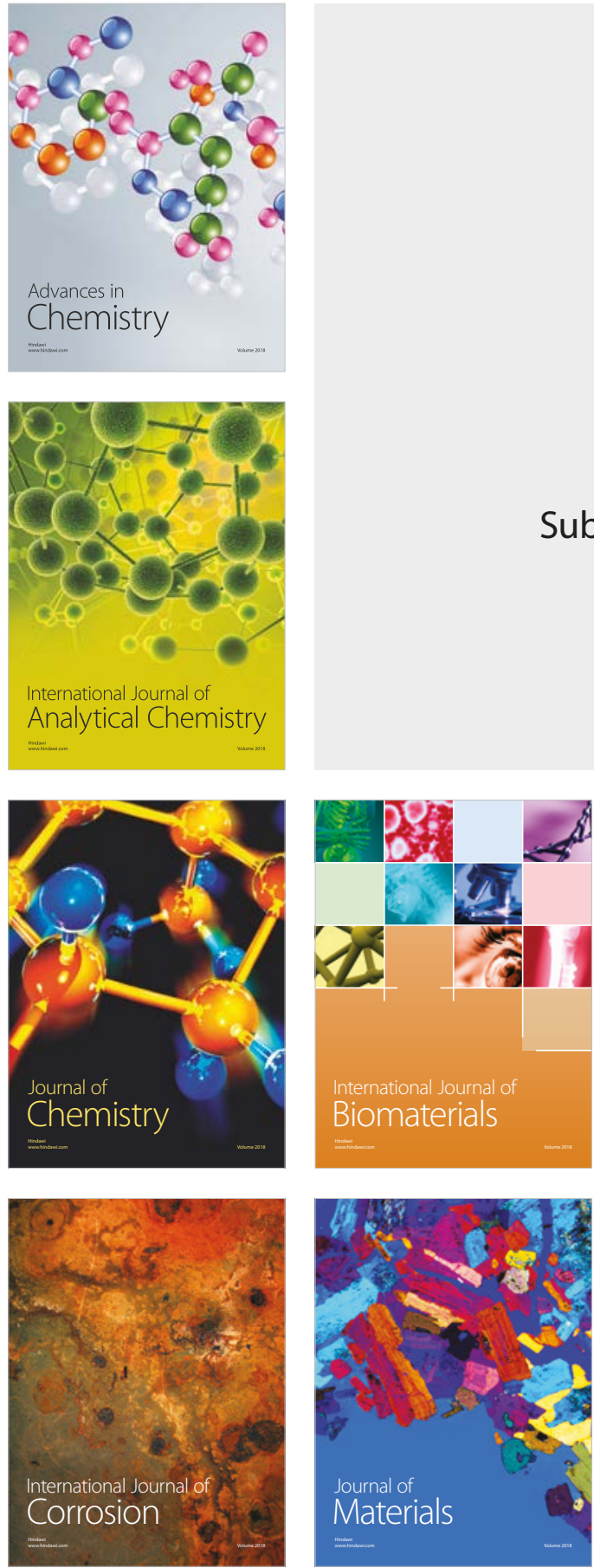

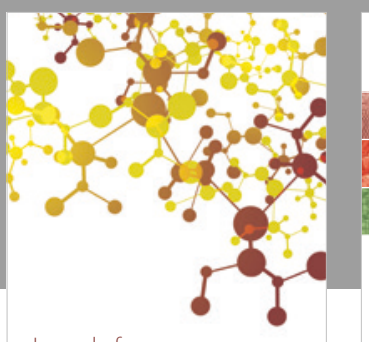

Journal of

Applied Chemistry
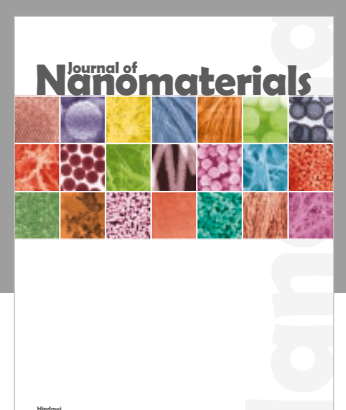

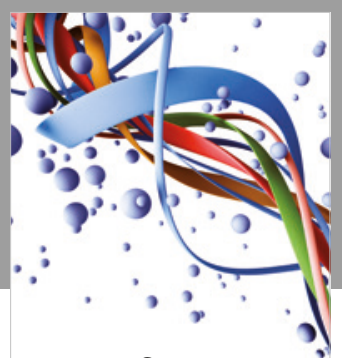

Scientifica

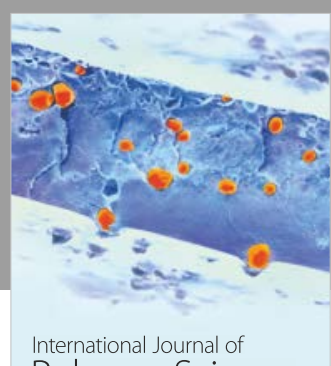

Polymer Science

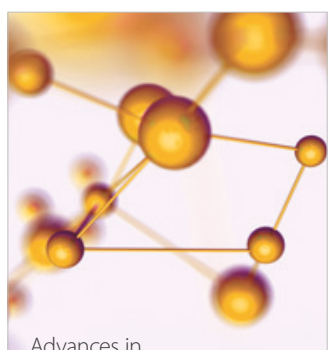

Physical Chemistry
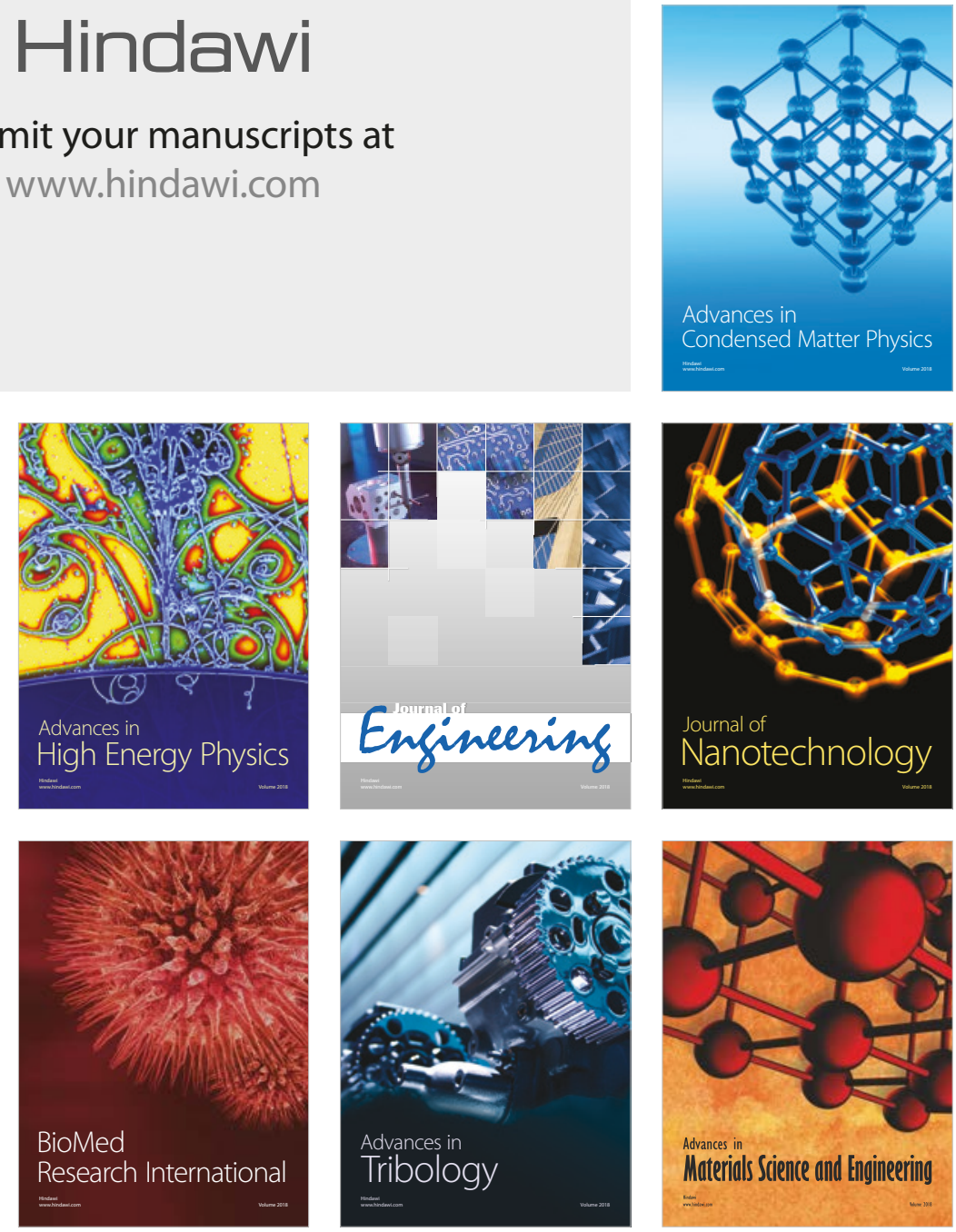